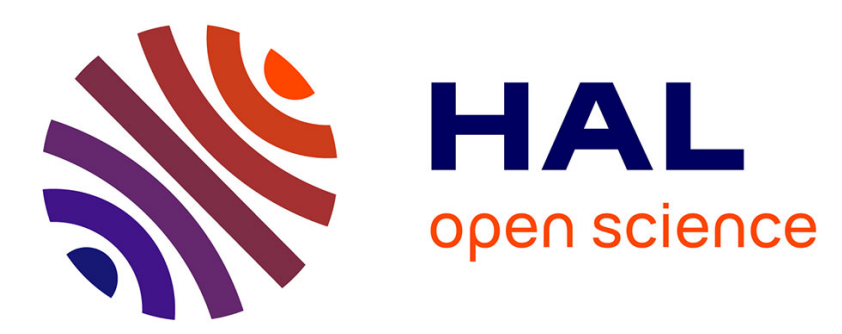

\title{
Testing a predicting model for frost resistance of winter wheat under natural conditions
}

Christophe Lecomte, Alex Giraud, Véronique Aubert

\section{To cite this version:}

Christophe Lecomte, Alex Giraud, Véronique Aubert. Testing a predicting model for frost resistance of winter wheat under natural conditions. Agronomie, 2003, 23 (1), pp.51-66. 10.1051/agro:2002068 . hal-00885970

\section{HAL Id: hal-00885970 \\ https://hal.science/hal-00885970}

Submitted on 1 Jan 2003

HAL is a multi-disciplinary open access archive for the deposit and dissemination of scientific research documents, whether they are published or not. The documents may come from teaching and research institutions in France or abroad, or from public or private research centers.
L'archive ouverte pluridisciplinaire HAL, est destinée au dépôt et à la diffusion de documents scientifiques de niveau recherche, publiés ou non, émanant des établissements d'enseignement et de recherche français ou étrangers, des laboratoires publics ou privés. 


\title{
Testing a predicting model for frost resistance of winter wheat under natural conditions
}

\author{
Christophe LeCOMTE*, Alex GIRAUd, Véronique AuberT \\ INRA, Unité de Génétique et d'Amélioration des Plantes, 17 rue Sully, BP 86 510, 21065 Dijon Cedex, France
}

(Received 16 November 2000; accepted 23 April 2002)

\begin{abstract}
The current knowledge of the winter frost hardiness and of the hardening and dehardening process of wheat (Triticum aestivum L. Thell.) makes it possible to elaborate a prediction model, including the genotype, the growth stage of the plant, the temperatures allowing hardening, and the speed and duration of hardening and dehardening. For each of these factors, several hypotheses were considered. Combination of these different hypotheses led to 24 potential models. Each of them was tested with data obtained under natural conditions, over 10 different winters. The prediction of the resistance level was good for the first frost wave, showing that a convenient predicting model can be based on relatively easy hypotheses. Conclusions can be made on certain hypotheses such as the susceptibility level at the coleoptile stage, the stage range where the maximal resistance increases, and the pattern of the hardening speed. For the subsequent frost waves, the divergence between the predicted and the observed resistance thresholds increased, irrespective of the leaf stage in the observed range. We show the role of the accumulated dehardening and the long time exposure to temperatures near the plant frost resistance threshold in the decrease of frost resistance. Nevertheless, other factors have to be considered in order to correctly predict the frost resistance thresholds for the second, third and subsequent frost periods.
\end{abstract}

frost resistance / modeling / wheat / genotypic effect

Résumé - Test d'un modèle de prévision de la résistance au gel du blé tendre d'hiver en conditions naturelles. Les connaissances acquises sur la résistance au gel hivernal et sur les processus d'endurcissement et de désendurcissement du blé (Triticum aestivum L. Thell.) permettent d'envisager l'élaboration d'un modèle de prévision qui prend en compte le génotype, le stade de la plante, les plages de températures qui permettent l'endurcissement, la vitesse et la durée de l'endurcissement et du désendurcissement. Pour chacun de ces facteurs, plusieurs hypothèses ont été envisagées. La combinaison de ces différentes hypothèses conduit à considérer 24 modèles potentiels. Chacun a été évalué à l'aide de données recueillies en conditions naturelles, au cours de 10 hivers. On obtient une bonne prévision des seuils de résistance au gel pour le premier coup de froid, et l'on peut conclure sur un certain nombre d'hypothèses comme le seuil de sensibilité au stade coléoptile, la gamme de stades au cours de laquelle la résistance maximale s'accroît, et la forme de la vitesse d'endurcissement. Pour des coups de froid ultérieurs, la divergence entre les seuils de résistance prévus et observés s'accroît avec le nombre de coups de froid, indépendamment du stade foliaire, dans la gamme de stades que nous avons explorée. Parmi les facteurs responsables de l'affaiblissement des plantes, nous mettons en évidence le rôle du désendurcissement cumulé et de l'exposition prolongée à des températures proches du seuil de résistance. Mais une prévision correcte de la résistance au gel pour des secondes, troisièmes, ... périodes de gel imposera de prendre en compte d'autres facteurs comme la satisfaction des besoins en vernalisation.

résistance au gel / modélisation / blé tendre / effet génotypique

\section{INTRODUCTION}

In France, winter frost damage on wheat (Triticum aestivum L. Thell.), leading to the death of plants and effects on yield, occurs approximately once in every ten years $[3,5,6]$. Slight effects are more frequent, consisting of more or less serious leaf damage. On the other hand, frost damage is a major problem for winter crops in countries where the winter is regularly severe (especially in Central Europe and North America).

Studies on frost hardiness of cultivated plants have been carried out for more than twenty years, and a large part of the cold acclimation mechanisms have been described: changes in plant behavior, and conditions attached to the plants or to their environment, allowing adaptation to the cold. But despite this large number of studies, those aimed at predicting frost 
hardiness are sparse and recent. For cereals, only Fowler et al. [12] have proposed a prediction, based on only one genotype and based on an artificial frost resistance test. This is largely due to the very high complexity of the plant and/or environmental factors involved in cold acclimation $[1,16,17$, $23,26]$. The genetic control of this character is also very complex, with 15 of the 21 chromosome pairs in bread wheat being involved $[2,30]$.

Additionally, it is particularly difficult to characterize correctly frost hardiness under natural conditions. There are many reasons for heterogeneity, and various factors limiting or increasing damage. The changing frost intensity between situations leads to major variation in damage, and even to changes in the classification of genotypes [8,9, 11]. Another difficulty results when observations made under controlled conditions are extrapolated to the field. In order to evaluate acquired resistance by field cultivated plants, authors have cut samples of the plants, then exposed them to a progressive low temperature range treatment under controlled conditions, and observed the temperature at which damage began to appear [10, 27]. But this operation reduces the number and the diversity of plants (for instance: the diversity of genotypes) which it is possible to evaluate, and under these conditions, it can be shown that the temperatures at which damage occurs are often higher than those observed under natural conditions. Since 1950, INRA has maintained an experimental system of rolling greenhouses located in Chaux-des-Prés, in the Jura Mountains, allowing the evaluation of frost damages without any protecting snow cover, without any transplantation of the plants, and limiting the heterogeneity of the environment (see description below). All the new entries of cereal cultivars registered in France are evaluated there for their frost hardiness, following a previously described procedure [21], in order to establish the official note of frost resistance [14].

In order to show the best level of frost resistance, the plant has to be hardened. We call "hardening" the active adaptation process allowing a plant to get more resistant to frost. This process requires time and specific environmental conditions, especially sufficient low temperature. The opposite process, the "dehardening", is the active process by which a plant loses resistance. Therefore, frost hardiness (or frost resistance) is a state of the plant, increasing or decreasing by the process of hardening and dehardening, and the frost hardiness can be evaluated by the temperature below which damage begins to appear. Therefore, the frost hardiness can be expressed on a ${ }^{\circ} \mathrm{C}$ scale.

Among the plant characteristics that play a part in frost hardiness, the most important are:

- The genotype, being more or less tolerant to frost [7, 9, 23]. Genotype differences for frost resistance are completely revealed when plants have reached a sufficient growth stage and are correctly hardened. Under such conditions, bread wheat shows a great genetic variability for maximal frost resistance $[7,23]$. These values are linked to the official notes of frost resistance [14, 23].

The genotype also plays a secondary part in the duration of hardening and dehardening: the average duration of hardening is 4 weeks $[18,28]$, but our own observations carried out in Chaux-des-Prés showed that the duration of hardening can fluctuate from 3 to 5 weeks. The genotype also has a secondary effect on the ability to reharden after a dehardening period [1, 16, 28, 29].

- The plant stage: Koller [20] and Roberts [29] described the time course of the maximal frost resistance depending on the growth stage of wheat. The maximal resistance is first low at the coleoptile stage and rapidly reaches a high level, peaking when tillering starts [20], which corresponds to 34 leaf stages [25], or even earlier, as a high frost resistance level is possible with 1.5 leaves [29].

Several environmental factors cause variations in frost response $[23,24,26]$ :

- The temperature, the plants are exposed to plays the most important part, and the possibilities of hardening are directly related to the decrease in temperature. Three stages in the hardening process for herbaceous plants have been described by Kacperska-Palacz [19], in relation to the temperature. Gusta and Fowler [15] showed that wheat grown at a constant $10^{\circ} \mathrm{C}$ partially acclimated to cold. At $20^{\circ} \mathrm{C}$, no acclimation occurs and, exposed to this temperature, a previously hardened wheat plant rapidly loses its frost resistance. Paquin [26] considered that the threshold for the beginning of cold acclimation in wheat is $15^{\circ} \mathrm{C}$. Maintaining a high level of frost resistance is possible only if the temperature stays under $0{ }^{\circ} \mathrm{C}$. As soon as it exceeds $0{ }^{\circ} \mathrm{C}$, some dehardening occurs $[15,28]$. Following that, and considering that the bounds of the stages described by Kacperska-Palacz [19] are not precise, it can be assumed that the relationship between the level of frost resistance the plants can achieve and the temperature is a linear relationship, delimited by the temperatures $15^{\circ} \mathrm{C}$ for the minimal level of hardiness, and $0{ }^{\circ} \mathrm{C}$ for the maximal level of hardiness.

The way the temperatures occur is also important: plants require time to harden, and a sudden frost can cause major damage, even if the level of temperature achieved is not very low. Pomeroy et al. [28], with the wheat cultivar Kharkov, showed that the maximal resistance is achieved in 4 weeks when hardening conditions are favorable (particularly the presence of a growth period before the hardening period). Acquisition of frost tolerance is faster at the beginning of hardening and decreases progressively during the 4 weeks, so that $90 \%$ of maximal resistance is obtained by 3 weeks. These conclusions are corroborated by studies on other species: Herzog [18] indicated the same hardening duration in Faba beans, but considered hardening to be a linear process (with a constant speed).

The dehardening process occurs if the hardiness allowed by the temperature the plants are exposed to is less than the hardiness previously achieved. A certain dehardening occurs as soon as temperatures are higher than $0{ }^{\circ} \mathrm{C}$. Dehardening is slow for temperatures still near $0{ }^{\circ} \mathrm{C}$, but more rapid as the temperature increases: Gusta and Fowler [15] showed that completely hardened wheat plants (cv. Kharkov) lost around half of their resistance at $10{ }^{\circ} \mathrm{C}$ over 5 days, but that dehardening was complete in the same time at $20^{\circ} \mathrm{C}$. Herzog [18] observed in Faba beans that frost resistance was reduced by half after 5 days at $10^{\circ} \mathrm{C}$, while at $15^{\circ} \mathrm{C}$ it was completely gone in the same time. For Pomeroy et al. [28], dehardening was perceptible as early as after 6 hours at $20^{\circ} \mathrm{C}$. 
After a dehardening period, a relatively short time is sufficient to prevent wheat from re-hardening to a level as high as previously. One week of dehardening at $10{ }^{\circ} \mathrm{C}$ or $96 \mathrm{~h}$ at $20^{\circ} \mathrm{C} / 15^{\circ} \mathrm{C}$ effectively prevented any rehardening to a high level of resistance $[15,28]$.

Even though in controlled environments it is possible to keep a constant and very high level of frost resistance at temperatures slightly below $0{ }^{\circ} \mathrm{C}$, many authors generally observed a progressive decrease of the hardening possibilities of cereal plants during winter $[1,15,17,26,28,29]$. This decrease is attributed to the conjunction of several plant weakening factors (dehardening periods, freezing and thawing alternance, repetitive occurrence of low temperatures near the resistance threshold of the plant), and also to the completion of the vernalization needs. However, it is interesting to notice that this decrease can be very low, and even non-existent for certain genotypes [1]. Pomeroy et al. [28] considered that winter survival differences between genotypes have to be related to the keeping of the re-hardening possibilities until spring. This characteristic, together with a lower hardening potential, explains the higher vulnerability of winter barley to spring frost, as compared with wheat. These effects are not quantified and it is very difficult to take them into account in order to predict the frost resistance.

- The light intensity. The hardening process depends on both light and temperature: light allows energy accumulation in plants, required for hardening, while temperature determines the frost resistance level reachable by the plants. Pomeroy et al. [28] showed that a wheat plant is able to harden to a high level in a short time if exposed to the required conditions for at least one week before hardening, including sufficient light and at least 10 to $15^{\circ} \mathrm{C}$. We considered that these conditions are the most frequently encountered in natural environments, and that light is not a limiting factor of the hardening process.

- A snow cover. even very thin, has a great protecting effect against frost. This is a main obstacle for the evaluation of frost resistance in natural environments, enhancing the interest of specific equipment, as in Chaux-des-Prés, which avoids any snow cover. In order to circumvent the protecting effect of snow, other authors exposed the plants under controlled frost conditions, with the disadvantages discussed above.

- Other environmental factors have an influence on the winter survival of the plants: the presence of ice on the surface of plants can rapidly be followed by asphyxiation, a decrease in the resistance, and the death of the plants [22]; the nature and moisture of the soil can lead to movement, eventually causing the severing of roots or rhizomes, which can threaten the survival of the plants [6]. The moisture of the soil generally has first a positive effect, delaying the decrease of the temperature in the soil. But it then has an aggravating effect, considering that ice conducts the cold better than water [26]. Additionally, specific diseases are able to develop under cold conditions or under a snow cover. Another great asset of a rolling greenhouses system is to make it possible to control all of these environmental factors.

We previously demonstrated [24] that a prediction of the evolution of the frost resistance of a winter wheat crop could be made, involving genotype, the plant stage, and the temperatures the plants are exposed to, including several hypotheses about some of these factors. The system used in Chaux-des-Prés makes it possible to validate it in natural conditions and to get conclusions about the subjacent hypothesis. We tried to build a model using the simplest input parameters possible (temperatures, genotypic characteristics), in order to make its accessibility easier.

We first describe how the model is built, and we then propose a test over ten years, under natural conditions, of different versions of the model. Finally we discuss the accuracy of the model under different modes of frost appearance, particularly for the first frost wave (or frost stress) resulting in damage, or for situations where several successive frost stresses occurred.

\section{MATERIALS AND METHODS}

\subsection{Basic hypotheses and presentation of the model}

We recorded the temperature $2 \mathrm{~m}$ above the soil surface, although also noting the surface temperature and that in the soil, in order to make it possible to transpose the prediction to other situations, where only the standard temperature is available.

The leaf stage is expressed according to a decimal scale, the length of the last growing leaf being measured in tenths of the preceding leaf. We assumed that the rhythm of leaf appearance (phyllochron) is constant, as it is expressed in the sum of daily mean temperatures above zero [25].

The model was elaborated according to the following stages:

- We first determined the minimal and maximal limits for frost resistance: $\boldsymbol{M i n} \boldsymbol{R}$ is the minimal resistance, observed when no hardening occurred; we assumed it is independent of genotype and plant stage; MaxR is the maximal frost resistance, achieved at the end of the hardening process; it depends on genotype and plant stage (paragraph 1.1).

- We then determined the potential frost resistance on day $d$ Pot $_{\boldsymbol{d}}$, varying between MinR and MaxR, according to the daily mean temperature $\boldsymbol{T} \boldsymbol{m}$ (paragraph 1.2).

- Finally, we calculated $\boldsymbol{d} \boldsymbol{R}$, the daily variation of frost resistance, deducted from the potential resistance determined on the same day and from the resistance achieved on the previous day (paragraph 1.3).

For a certain genotype, the model estimates every day the temperature below which the first leaf damage can occur.

\subsubsection{Minimal (MinR) and maximal (MaxR) frost resistance}

For bread wheat, almost the whole frost resistance variability is described by a 9-cultivar scale, used for the official tests of frost resistance. Our yearly observations in Chaux-des-Prés did not allow us to conclude in favor of genotypic differences for frost resistance if no hardening has occurred. Consequently, we assumed that all genotypes have 
Table I. Official scale and control bread wheat cultivars used to characterize frost tolerance. The resistance thresholds indicated correspond to appearance of the first leaf necroses; cultivar Rex is a spring wheat.

\begin{tabular}{|c|c|c|c|}
\hline Official scale of frost resistance & Cultivar & Symbol & Maximal resistance thresholds $R s\left({ }^{\circ} \mathrm{C}\right)$ \\
\hline 1 & REX & REX & -12 \\
\hline 1.5 & & & -13 \\
\hline 2 & & & -14 \\
\hline 2.5 & MAGALI & MAG & -15 \\
\hline 3 & CHAMPLEIN & $\mathrm{CHA}$ & -16 \\
\hline 3.5 & & & -17 \\
\hline 4 & & & -18 \\
\hline 4.5 & CAPPELLE & CPL & -19 \\
\hline 5 & & & -20 \\
\hline 5.5 & & & -21 \\
\hline 6 & CAPITOLE & CPI & -22 \\
\hline 6.5 & & & -23 \\
\hline 7 & MOISSON & MOI & -24 \\
\hline 7.5 & & & -25 \\
\hline 8 & ARMINDA & ARM & -26 \\
\hline 8.5 & & & -27 \\
\hline 9 & COMTAL & $\mathrm{COM}$ & -28 \\
\hline$(11) *$ & CHEYENNE & CHE & -32 \\
\hline
\end{tabular}

* The mark for Cheyenne is outside the official scale of wheat frost resistance. It is therefore a theoretical one, corresponding to the different behavior observed between Cheyenne and Comtal, this cultivar being the most hardy control in the official scale.

the same frost resistance threshold $\operatorname{MinR}=-6{ }^{\circ} \mathrm{C}$ when plants are not cold-acclimated.

When hardening is complete, the resistance shown by plants is maximal, and we also determined the corresponding thresholds for each cultivar. At the stages allowing the expression of the maximal resistance, the values range from $\boldsymbol{R} \boldsymbol{s}=-12{ }^{\circ} \mathrm{C}$ for the spring cultivar Rex to $\boldsymbol{R} \boldsymbol{s}=-32{ }^{\circ} \mathrm{C}$ for the cultivar Cheyenne (Tab. I).

For early stages, these values cannot be achieved. According to the conclusions of Koller [20], we evaluated the maximal frost resistance at the coleoptile stage at near to $\boldsymbol{R} \boldsymbol{c}=$ -10 up to $-12{ }^{\circ} \mathrm{C}$. Thus, we decided to test both values in the models we proposed. We also assumed that maximal resistance increases linearly from an initial stage $i L S$, which is not exactly determined, up to a final stage $\boldsymbol{f L S}$, where it reaches the genotypic-dependent value $R s$ [24]. As the authors also did not agree about the value of fLS, we tested several stage ranges for the increase of MaxR: an initial stage of 0 or 0.5 leaves, and a final stage of $2.5,3.0$ or 3.5 leaves.

For a given genotype, MaxR was modeled depending on the leaf stage according to the following equations:

$$
\begin{aligned}
& \text { If } L S<i L S: \quad \operatorname{MaxR}=R c \\
& \text { If } i L S<L S<f L S: \operatorname{Max} R=\frac{(R s-R c)}{(f L S-i L S)} \times(L S-i L S)+R c
\end{aligned}
$$

$$
\text { If } f L S<L S: \quad \operatorname{Max} R=R S
$$

where $L S$ : leaf stage of plants; iLS: initial leaf stage (corresponding to the beginning of MaxR increase); $f L F$ : final leaf stage (corresponding to the end of MaxR increase); $R c$ : maximal resistance at the coleoptile stage; $R s$ : maximal resistance threshold for the genotype considered.

The theoretical leaf stage was calculated every day, according to both the cumulated daily mean temperature above zero and the phyllochron. The phyllochron is determined by the observation of the leaf stage on two different dates related to the cumulated daily mean temperature above zero. In Chaux-des-Prés, the phyllochron often gives values between 60 and 80 degrees $\times$ day.

\subsubsection{Potential frost resistance on day $d\left(\right.$ Pot $\left._{d}\right)$}

As outlined above, we assumed that only temperature fluctuations are involved in determining the potential frost resistance, according to a linear relationship. The potential resistance $\operatorname{Pot}_{d}$ fluctuates between $\operatorname{MinR}$ (no resistance) when the daily mean temperature $T m$ is higher than $15^{\circ} \mathrm{C}$ and $\operatorname{MaxR}$ (maximal resistance) when $T m$ is lower than $0{ }^{\circ} \mathrm{C}$. We also assumed that the potential frost resistance does not depend on whether plants are hardening or dehardening. Hardening occurs when the temperature the plants are exposed to determines a higher potential frost resistance than the already acquired resistance. Dehardening occurs in the opposite direction when potential frost resistance is lower than the already acquired resistance. 
Table II. Method for calculating the frost resistance, according to the daily mean temperature and frost resistance achieved on previous day, in the case of a constant hardening speed and an hardening duration of 28 days.

\begin{tabular}{|c|c|c|c|c|}
\hline $\begin{array}{l}\text { Condition on the } \\
\text { daily mean } \\
\text { temperature }\end{array}$ & $\begin{array}{l}\text { Daily potential frost } \\
\text { resistance } \\
\text { (Relation (2)) }\end{array}$ & $\begin{array}{l}\text { Condition on the } \\
\text { resistance achieved } \\
\text { on day } d-1\end{array}$ & $\begin{array}{l}\text { Variation of frost resistance } \\
\quad \text { (Relations (3) or (4)) }\end{array}$ & Resistance on day $d$ \\
\hline \multirow[t]{2}{*}{ If $T m \geq 15$} & $\operatorname{PotR}_{d}=\operatorname{MinR}$ & If $R_{d-1}=$ Pot $R_{d}$ & $d R=0$ & $R_{d}=R_{d-1}=\operatorname{Min} R$ \\
\hline & & If $R_{d-1}<P o t R_{d}$ & $d R=T m \times \frac{(M i n R-R s)}{100}$ & $R_{d}=\operatorname{Min}\left[\left(R_{d-1}+\Delta R\right) ; \operatorname{Min} R\right]$ \\
\hline \multirow[t]{4}{*}{ If $0<\operatorname{Tm}<15$} & $\operatorname{PodR}_{d}=\operatorname{Max} R+\frac{T m}{15}$ & If $R_{d-1}>$ Pot $R_{d}$ & $d R=\frac{\operatorname{Max} R-\operatorname{Min} R}{28} \times\left(1-\frac{T m}{15}\right)$ & $R_{d}=\operatorname{Max}\left[\left(R_{d-1}+\Delta R\right) ; \operatorname{Pot} R_{d}\right]$ \\
\hline & $\times(\operatorname{MinR}-\operatorname{Max} R)$ & & & \\
\hline & & If $R_{d-1}=$ Pot $R_{d}$ & $d R=0$ & $R_{d}=R_{d-1}=\operatorname{Pot}_{d}$ \\
\hline & & If $R_{d-1}<P o t R_{d}$ & $d R=\operatorname{Tm} \times\left(\frac{\operatorname{Min} R-R S}{100}\right)$ & $R_{d}=\operatorname{Min}\left[\left(R_{d-1}+\Delta R\right) ; \operatorname{Pot} R_{d}\right]$ \\
\hline \multirow[t]{2}{*}{ If $T m \leq 0$} & $\operatorname{Pot}_{d}=\operatorname{Max} R$ & If $R_{d-1}>\operatorname{Pot}_{d}$ & $d R=\left(\frac{\operatorname{Max} R-\operatorname{Min} R}{28}\right) \times\left(1-\frac{T m}{15}\right)$ & $R_{d}=\operatorname{Max}\left[\left(R_{d-1}+\Delta R\right) ; \operatorname{Max} R\right]$ \\
\hline & & If $R_{d-1}=$ Pot $R_{d}$ & $d R=0$ & $R_{d}=R_{d-1}=\operatorname{Max} R$ \\
\hline
\end{tabular}

The relationship (2) between the potential frost resistance $\operatorname{Pot}_{d}$ and the outside temperature $T m$ is shown in Table II and illustrated in Figure 1 in a simulated case for the cultivar Moisson $\left(\mathrm{Rs}=-24^{\circ} \mathrm{C}\right)$. We adopted here the value $-12{ }^{\circ} \mathrm{C}$ for $R c$. MaxR increases from $R c$ to $R s$ between the stages $i L S$ and $f L S$.

\subsubsection{Calculation of the daily frost resistance $\left(R_{d}\right)$}

Increasing and decreasing frost resistance are not instantaneous responses. Both are adaptation processes, requiring energy from the plant and involving several physiological changes. Hence, cold hardening and dehardening require time.

\subsubsection{Hardening}

Two hypotheses for the hardening speed were tested, with a hardening duration of 4 weeks, the slight genotype effect on the duration of hardening being neglected (but it will be discussed below in order to improve the prediction of frost damage appearance with different genotypes):

1. As shown by Pomeroy et al. [28], we simulated the hardening speed by a proportionality relation with the difference $\left(\right.$ Pot $\left._{d}-R_{d-1}\right)$ :

$$
d R=a \times\left(\text { Pot }_{d}-R_{d-1}\right)
$$

where: $d R$ is the increase in frost resistance (or hardening speed, in $\left.{ }^{\circ} \mathrm{C} / \mathrm{day}\right)$, Pot $_{d}$ is the potential frost resistance on day $d, R_{d-1}$ is the frost resistance acquired on the previous day, $a$ is a coefficient depending on the duration of hardening. Establishing arbitrarily that, under constant $T m$, the difference $\left(P_{\text {ot }} R_{d}-R_{d}\right.$ ) has to be lower than $5 \%$ of the difference $\left(\right.$ Pot $_{d}$ $-\operatorname{MinR}$ ) after 28 days, the value of coefficient $a$ is deduced.
According to this hypothesis, hardening is faster at the beginning of the hardening period, and decelerates when the resistance comes to MaxR. Evolution of $R_{d}$, the acquired resistance for a given day, is asymptotic towards the Pot $R_{d}$ value. The daily increase of frost resistance (when Pot $R_{d}<$ $R_{d-1}$ ) was calculated as follows:

$$
d R=\{1-\exp [1 / 28+\log (0.05)]\} \times\left(\text { Pot }_{d}-R_{d-1}\right)
$$

2. As shown by Herzog [18], we also tested a constant daily hardening speed, so that potential frost resistance $P$ ot $R_{d}$ is reached in 28 days: $d R=\left(P o t R_{d}-\operatorname{MinR}\right) / 28$ where: $d R$ is the increase in frost resistance (or hardening speed, in ${ }^{\circ} \mathrm{C} /$ day), PotR $_{d}$ is the potential frost resistance on day ${ }_{\mathrm{d}}, \operatorname{MinR}$ is the minimal frost resistance.

Here, speed is only dependent on the difference between the daily potential frost resistance of the genotype $\operatorname{Pot}_{d}$ and the minimal frost resistance $M i n R$. The daily increase in frost resistance (when $\operatorname{Pot}_{d}<R_{d-1}$ ) was calculated as follows:

$$
\left.d R=\left(\operatorname{Pot}_{d}-\operatorname{MinR}\right) / 28\right) .
$$

In both cases, the hardening speed depends on the temperature through Rpot $_{d}$. Its expression related to the temperature is presented in Table II.

\subsubsection{Dehardening}

To build our model, we decided to use the conclusions of Gusta and Fowler [15], assuming that the dehardening speed was proportional to the average temperature $\mathrm{Tm}$. It is equal to 0 if $\mathrm{Tm}=0{ }^{\circ} \mathrm{C}$, it is two times higher at $20^{\circ} \mathrm{C}$ than at $10^{\circ} \mathrm{C}$, and dehardening has to be complete in 5 days at $20^{\circ} \mathrm{C}$. 


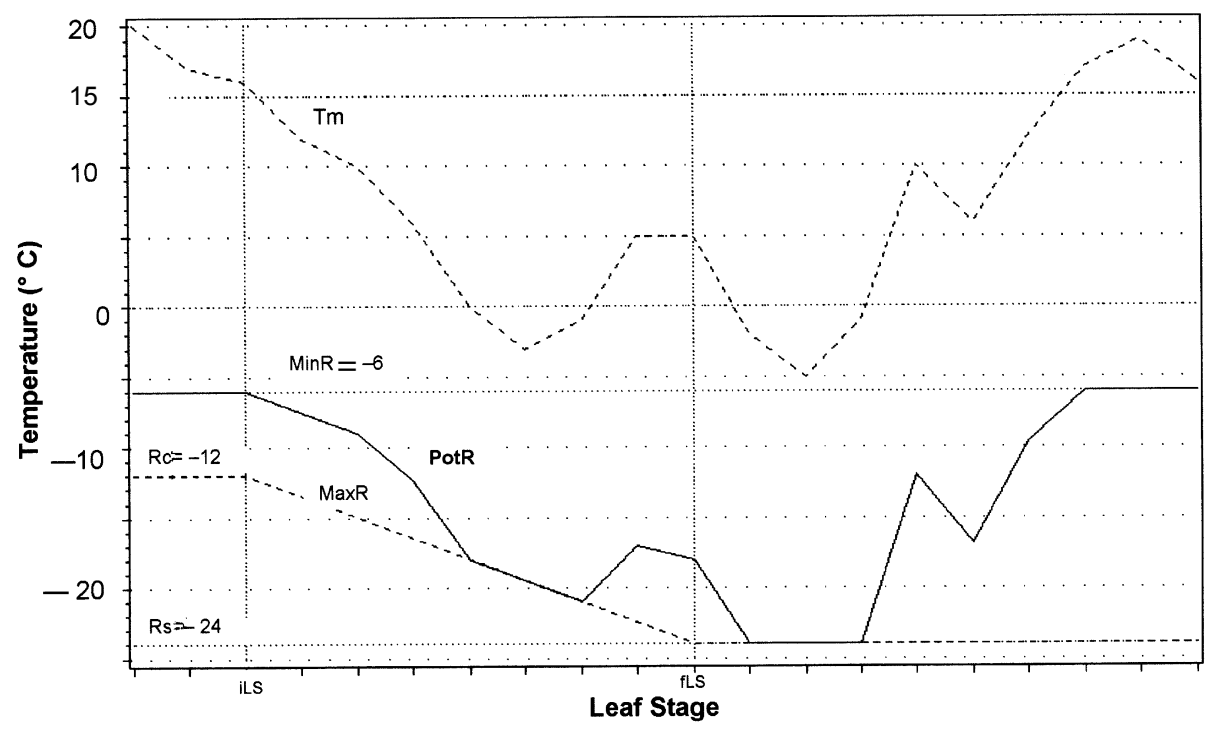

Figure 1. Evolution of $\operatorname{Pot}_{d}$, daily potential frost resistance of a wheat plant, according to its stage and the outside mean temperature (example of the cultivar Moisson in a fictitious case).

As for hardening, genotypic differences for the speed or duration of dehardening probably exist. Taking into account these differences requires precise knowledge of the genotypes to be tested, especially concerning this trait. As this condition was not met, we chose to neglect these genotypic differences. We also did not account for differences on dehardening speed that related to the plant stage and the resistance level previously achieved. Other authors studying dehardening speed worked with greatly hardened plants, at a stage allowing the expression of the maximal resistance. We considered therefore that the dehardening speed is determined by the difference between the minimal frost resistance MinR and the maximal frost resistance threshold $R s$, depending on the genotype. According to these principles, the daily dehardening speed is expressed as follows:

$$
d R=[(\operatorname{MinR}-R s) / 100] \times T m .
$$

\subsubsection{Conclusion: construction of the model and input variates}

Based on the hypotheses and relationships presented above, the calculation of frost resistance was performed each day as shown in Table II. $R_{d}$ is the value of frost resistance on day $d$ (in ${ }^{\circ} \mathrm{C}$ ), $R_{d-1}$ is the value of frost resistance on day $d-1$.

$\operatorname{Pot}_{d}$ is the value of potential frost resistance on day $d$. It was calculated according to equation (2), depending on the daily mean temperature. It depends on MaxR, the maximal resistance of the genotype at a given stage. MaxR was itself determined each day using equation (1) where $R s$, a genotypedependent trait, is given in Table I. The leaf stage was determined from accumulated daily mean temperatures above zero and the experimentally calculated phyllochron.

- If $R_{d-1}>\operatorname{Pot}_{d}$ (frost resistance acquired on the previous day corresponds to a higher temperature than the one corresponding to the potential resistance on day $d$ ), then the frost resistance increases. It is calculated by equation (3.1) or (3.2) and is limited by $\operatorname{Pot} R_{d}$ :

$$
R(d)=\operatorname{Max}\left[\left(R_{d-1}+d R\right) ; \operatorname{Pot}_{d}\right] .
$$

- If $R_{d-1}<\operatorname{Pot}_{d}$ (frost resistance acquired on the previous day corresponds to a lower temperature than the one corresponding to the potential resistance on day $d$ ), then the frost resistance decreases according to equation (4), and it is limited by $\operatorname{Pot}_{d}$ :

$$
R_{d}=\operatorname{Min}\left[\left(R_{d-1}+d R\right) ; \operatorname{Pot}_{d}\right] .
$$

The input variates of the model are the following:

- The daily minimal and maximal temperatures. The daily mean temperature and the daily mean temperature above zero are calculated from both of these data.

- The genotypic official note of frost resistance, making it possible to determine the maximal frost resistance threshold $R s$. The genotypic duration of hardening is fixed by default to four weeks.

- The sowing date. The emergence date is facultative: by default, it is determined from the sum of temperatures between sowing and emergence: Gate [13] estimated it to be 120 degrees $\times$ days when conditions for emergence are good.

- The phyllochron. Different values of the phyllochron lead to major variations of the theoretical leaf stage. Thus this data make it possible to improve appreciably the determination of the stage and therefore the prediction of frost resistance, especially for the young stages.

According to the different hypotheses stated, the model for the prediction of frost resistance takes 24 different forms ( 2 hardening speeds $\times 2 R c$ thresholds $\times 6$ stage ranges). For the following discussion, we call each of these different forms "model 1" to "model 24". 


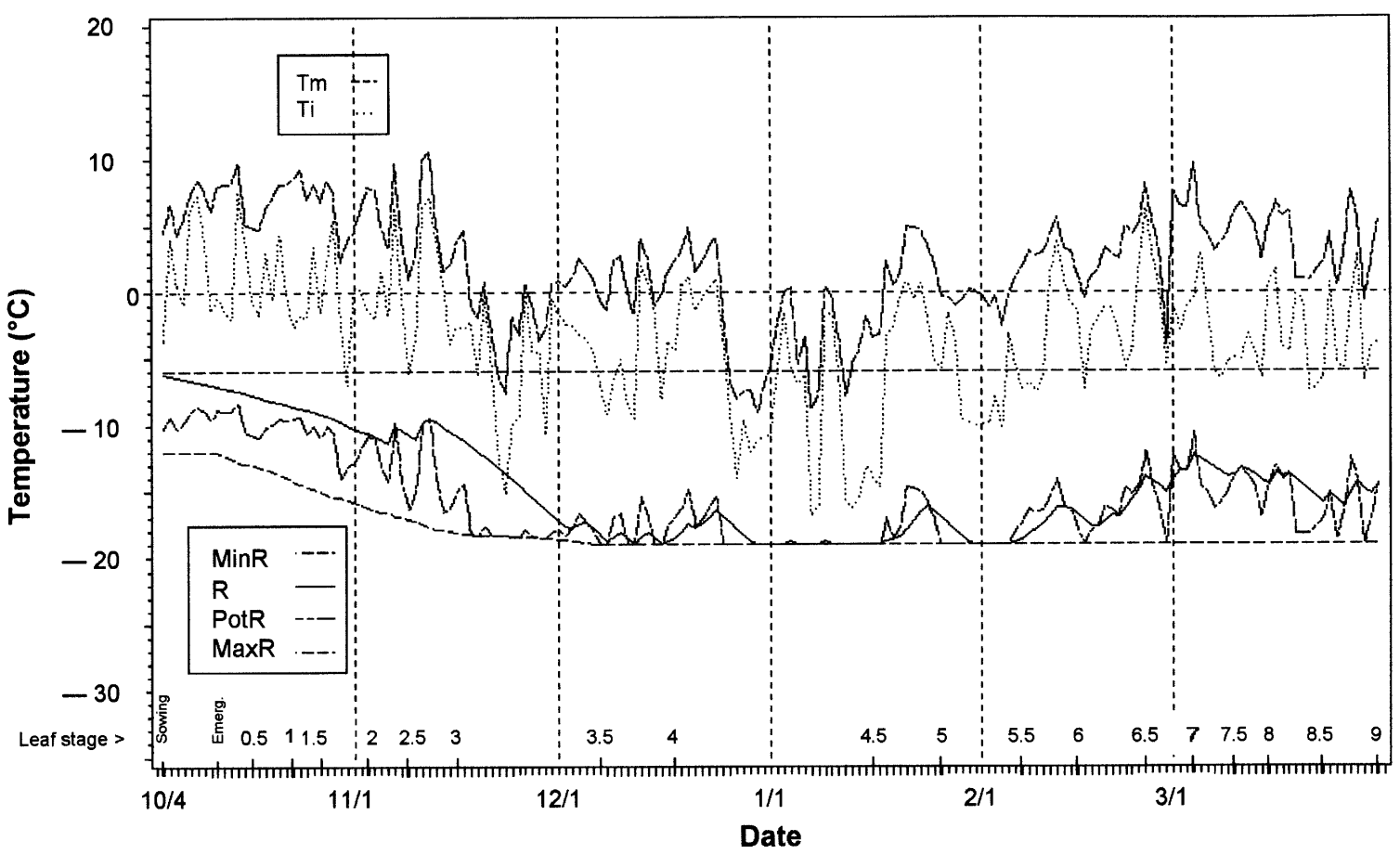

Figure 2. Calculated frost resistance of the cultivar Cappelle $\left(\operatorname{MaxR}=-19^{\circ} \mathrm{C}\right)$ during the winter $1996 / 1997$, by the model 18 .

\subsection{Collecting experimental data}

The test was performed during 10 winters at the INRA station in Chaux-des-Prés, France. This station is located at $879 \mathrm{~m}$ altitude in the Jura mountains, near the cold pole in France. Such harsh conditions made it possible to observe frost damage on a proportion of the tested genotypes almost every year. The station consists of two moving greenhouses covering nearly $300 \mathrm{~m}^{2}$. They are closed when there are precipitation risks and opened when the weather is clear. Therefore, we can evaluate the frost resistance of plants, controlling soil moisture as well as possible, and avoiding a protecting snow cover. Nine wheat cultivars were used as controls in order to evaluate frost resistance (Tab. I). Selected to represent almost the whole genetic variability for frost resistance of bread wheat, these cultivars were replicated 35 times in the field, to account for experimental heterogeneity (ground and moisture, proximity of borders).

Frost damage appears when the daily minimal temperature $T i$ is equal to or lower than the plants' acquired resistance. For moderate frost stresses, damage appears on the most sensitive cultivars; for more severe frosts, they progressively reach the most resistant cultivars. The model testing is based on the determination of the limit between the first cultivar in the scale without damage and the last cultivar damaged, observing the range of cultivars as the resistance increases. A theoretical resistance was calculated for each cultivar by the different models, and we compared this resistance with the minimum temperature recorded when frost stress occurred.

\subsection{Calculating divergence between predicted and observed values of frost resistance}

For each model, we calculated the divergence between the predicted value and reality as follows:

- The divergence is 0 if the last damaged cultivar fits well with the last predicted cultivar in the model (minimum temperature $T i$ is equal to or lower than the calculated resistance of the last damaged cultivar, and strictly higher than the calculated resistance of the first cultivar without damage, on the day of frost stress).

- The divergence is positive if the prediction overestimates resistance (calculated resistance of the last damaged cultivar corresponds to a strictly lower temperature than minimum temperature $T i$ ), and is equal to the difference $T i-\mathrm{R}$, where $R$ is the resistance of the last damaged cultivar, calculated on the day of frost stress.

- The divergence is negative if the prediction underestimates resistance (calculated resistance of the first cultivar without damage corresponds to a temperature higher than or equal to the minimum temperature $T i$ ), and is equal to the difference $T i-\mathrm{R}-0.1$, where $R$ is the resistance of the first cultivar without damage.

Due to the variability of the winter conditions between years and the increase of frost damage during the same winter, divergences are not always calculated from the same cultivars. As an illustration, Figure 2 shows the frost resistance calculated by model 18 for the cultivar Cappelle in the winter 1996/ 1997. That year, the last cultivar damaged by the first frost 
wave was Champlein whereas the simulation predicted damage on Cappelle (the minimal temperature $T i$ observed on Nov. 11 was $-15.1^{\circ} \mathrm{C}$, and the predicted resistance for Cappelle was $-13.7^{\circ} \mathrm{C}$ ). Therefore, the simulation underestimates the frost resistance of Cappelle (by $-15.1-(-13.7)-0.1=$ $\left.-1.5^{\circ} \mathrm{C}\right)$.

\subsection{Analysis of the divergences between prediction and reality}

Ten simulations were performed for each model out of the 10 years. Every one is characterized by a value of divergence between the prediction and reality at every frost wave. We calculated for each simulation: the average of the absolute value of divergences (more interesting than the average of raw values, because it avoids compensations), the amplitude of divergences, and the standard deviation of the divergences. This last criterion is almost the same as the square root of the average of the squares of the divergences. The Mean Square Error of Predictor (MSEP), is commonly used for this kind of evaluation; its square root uses the same unit as the divergence. We assumed that the best model had to minimize this last criterion, corresponding to the variability of the observed divergences.

An analysis of variance was performed for the absolute values of the divergence at the first cold wave, taking into account the year and model effects. The ANOVA model is written as follows:

$\mathrm{E}\left[D_{y m}\right]=\mu+A_{y}+B_{m}$ where:

$\mathrm{E}\left[D_{y m}\right]$ is the expected absolute value of divergence, for the year $y$ and the model $\mathrm{m}$;

$\mu$ is the general average;

$A_{y}$ is the year main effect;

$B_{m}$ is the model main effect.

There is no genotype effect because, as explained above, the divergence was calculated out of the last damaged cultivar and the first non-damaged cultivar, which can be different for every frost wave. Therefore, no comparison of genotypes was possible.

The kind of model is itself divided into four factors: the hardening speed ( 2 levels), the maximum resistance threshold at the coleoptile stage ( 2 levels), the initial stage from which maximum resistance begins to increase ( 2 levels), and the final stage for this increase ( 3 levels). The variance analysis model becomes:

$$
\begin{gathered}
\mathrm{E}\left[D_{y s c i f}\right]=\mu+A_{y}+B_{s}+C_{c}+D_{i}+E_{f} \\
+A B_{y s}+A C_{y c}+A D_{y i}+A E_{y f} \\
+B C_{s c}+B D_{s i}+B E_{s f}+C D_{c i}+C E_{c f}+D E_{i f} \text { where: }
\end{gathered}
$$

$\mathrm{E}\left[D_{y s c i f}\right]$ is the expected absolute value of divergence, with the hypotheses $s$ (speed), $c$ (maximum resistance at the coleoptile stage), $i$ (initial stage), $f$ (final stage), for the year $y$;

$\mu$ is the general average;

$A_{y}$ is the year main effect;
$B_{S}$ is the hardening speed main effect;

$C_{C}$ is the main effect of the maximal resistance at the coleoptile stage;

$D_{i}$ is the main effect of the initial stage for the increase of $\operatorname{MaxR}$;

$E_{f}$ is the main effect of the final stage for the increase of $\operatorname{MaxR}$;

$A B_{y s}, A C_{y c}, A D_{y i}$ and $A E_{y f}$ are the interaction terms between the year and the different hypotheses;

$B C_{s c}, B D_{s i}, B E_{s f}, C D_{c i}, C E_{c f}$ and $D E_{i f}$ are the two by two interaction terms of the different hypotheses.

\subsection{Explaining factors for divergences between prediction and reality}

After the first frost wave, plant weakening factors [23, 26] lead to lower frost resistance, and the models do not take them into account. Therefore, a progressive increase of the divergence between predicted and real resistance is expected during winter, related to the number, the lateness and the duration of frost waves. In order to explain the increase of the divergence, we calculated several variates describing the plant weakening, using only the one model which appeared to be the best from the previous analysis:

- the daily dehardening, and cumulated dehardening: from the start of the crop (cumDl), from the time the resistance reached the maximal resistance $\operatorname{MaxR}$ (cumD2), and from the time it reached the genotypic threshold $R s$ (cumD3); dehardening is given as raw values or as percentages, related to the frost resistance range $R s-M i n R$ of the last damaged cultivar;

- the duration of frost waves (Dur: number of days where the daily minimum temperature does not show a difference greater than $5{ }^{\circ} \mathrm{C}$ from the minimum of the period);

- and the number of days when the resistance stayed at a high level (NdMaxR: number of days where calculated resistance does not show a difference greater than $1{ }^{\circ} \mathrm{C}$ from the maximal resistance $\operatorname{MaxR}$ ).

We then studied the correlation between the divergences at each frost wave and the weakening factors, either out of all the data, or separating the data of the first and of the later frost waves. In order to identify the best combination of factors explaining the divergences, a linear regression model was also used, where covariates were introduced progressively, according to a determination coefficient $\left(\mathrm{r}^{2}\right)$ as high as possible. All of these analyses were performed with the SAS Institute software package (SAS Institute Inc.).

\section{RESULTS AND DISCUSSION}

\subsection{Characterizing the 10 years studied}

Yearly minimum temperatures were highly variable: from $-13{ }^{\circ} \mathrm{C}$ in $1989 / 1990$ to $-31.1^{\circ} \mathrm{C}$ in $1994 / 1995$. The timing of frost waves also varied between years (Tab. III). The minimum temperature in a year can be reached as soon as the first frost wave (1993/1994 and 1994/1995), or in certain years, much later. Correspondingly, the leaf stage at which the 


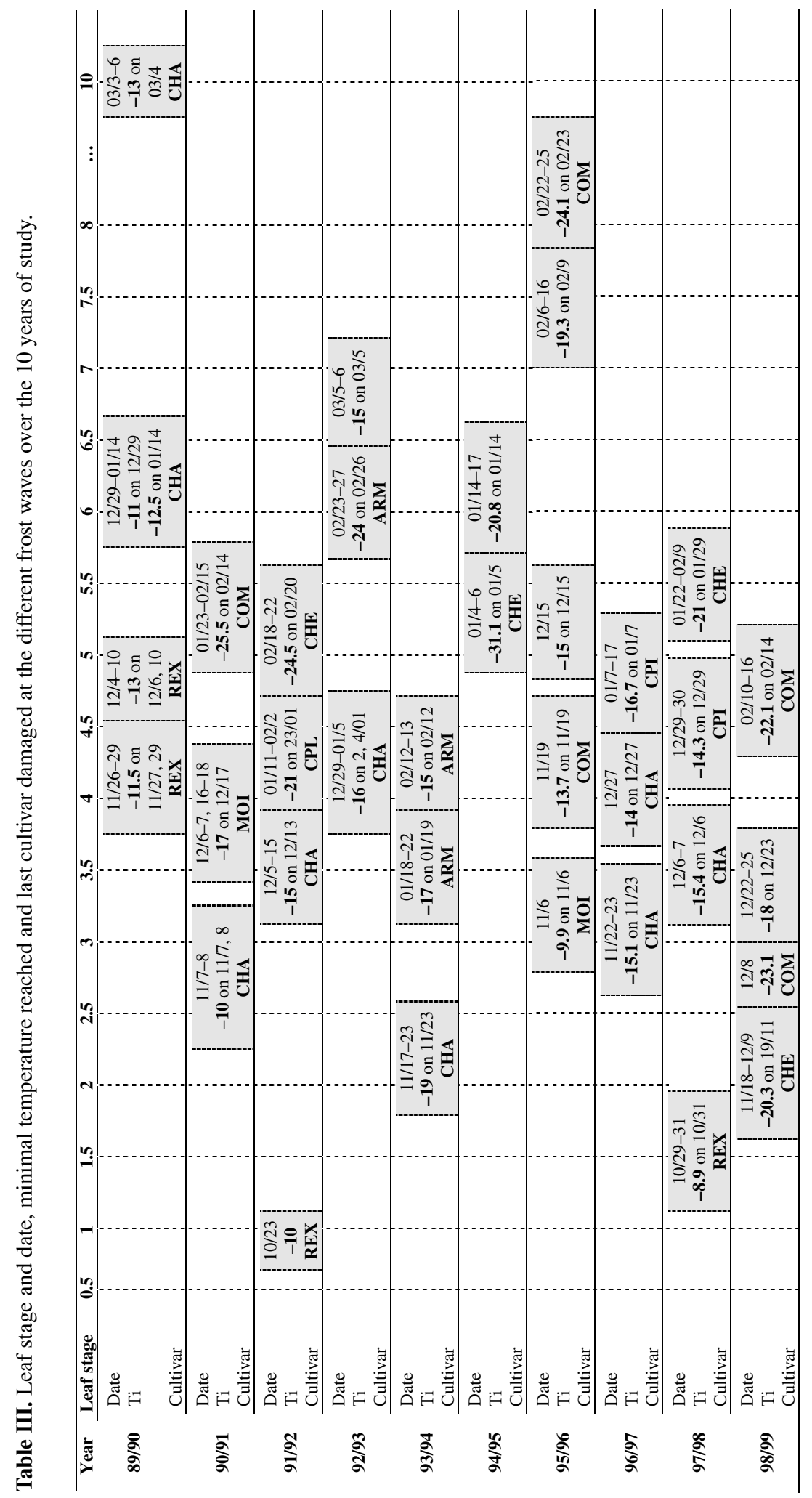


first frost wave occurred was also very variable (from 0.75 leaf in $1991 / 1992$ to 5.25 leaves in 1994/1995). We observed that for 5 of the 10 years, the first frost wave occurred before the 3 leaf stage and for 7 of the 10 years, it occurred before the 3.5 leaf stage. Therefore, the accuracy of prediction probably depends especially on hypotheses concerning the early stages.

The number of frost waves fluctuated from two in 1994/ 1995 to five in 1995/1996 (Tab. III). The last damaged cultivar changed in various years: for the first frost wave, it was often one of the most sensitive cultivars (from Rex to Champlein). But the last damaged cultivar was Moisson in 1995/1996 (6th cultivar in the range) and it was Cheyenne, the most hardy cultivar, in 1994/1995 and 1998/1999. As the frost waves followed one another during the winter, damage reached more and more hardy cultivars, and there was an increase in damage of the cultivars damaged at the first frost wave.

Hence, there was a great diversity of conditions during these 10 years, and a model able to predict correctly frost resistance of wheat here may be valid for a wide range of environments.

\subsection{Accuracy of prediction for the first frost wave}

\subsubsection{Comparison of the 24 models}

In three cases (1989/90, 1992/93 and 1994/95), the prediction was correct irrespective of the different hypotheses used (the absolute values of divergences were lower than $1{ }^{\circ} \mathrm{C}$ ) and for these three years, the leaf stage was greater than 4 leaves (Tab. IV and Tab. III). In 1997/98, divergences were low but they were positive or negative and the models showed small differences. Of the six other cases, the divergences distinguish the different models, with positive divergences in three cases (predicted resistance is greater than that observed: years 1990/91, 1995/96 and 1998/99) and with negative divergences in three other cases (years 1991/92, 1993/94 and 1996/97). These results show that the accuracy of prediction depends mainly on hypotheses concerning the early stages. Indeed, in all the situations where prediction did not fit well with the reality, the plants were young.

Individual divergences ranged from $-5.1{ }^{\circ} \mathrm{C}$ in $1993 / 94$ (No. 9) to $+6.1{ }^{\circ} \mathrm{C}$ in $1995 / 96$ (No. 1, 7 and 10). During both of these years, none of the models resulted in a completely satisfying prediction, but the accuracy of prediction varied greatly between models. The average of the absolute value of divergences ranged from 1.10 to $1.82{ }^{\circ} \mathrm{C}$, the amplitude of the divergences from 5.1 to $10.3{ }^{\circ} \mathrm{C}$ and the standard deviations from 1.60 to $2.81{ }^{\circ} \mathrm{C}$.

Table $\mathrm{V}$ indicates the results of the ANOVA, performed from the absolute values of divergences at the first frost wave. Variation explained by the ANOVA model was very high (up to $98.9 \%$ ). The year effect was by far the most important (68.9\% of the total variation). In comparison, the effect of the prediction model was relatively small, but significant. Among the different components of the model, the effects of the hardening speed and the final stage in the MaxR increase were significant. The significance of the effect of the maximum resistance threshold at the coleoptile stage is borderline (probability of 6\%). The models based on hardening at a constant speed led to lower divergence (1.25) than those based on a varying hardening (1.59). For the increase of maximal resistance MaxR, the models based on a final stage of 3.5 leaves led to the lowest divergence, 3 leaves being even better than 2.5 leaves. The initial stage had no effect. For the maximum resistance threshold at the coleoptile stage $R c$, divergence was lower with -12 than $-10^{\circ} \mathrm{C}$, but not significantly different. All interactions between the years studied and predictive model effects incorporated in the ANOVA model were significant, meaning that the responses were not consistent between years. This shows that evaluation of the different models must also take into account the stability of their results.

Using standard deviations of the models over the ten-year period (Tab. IV), we observed a great concordance with the previous conclusions. The models resulting in the lowest standard deviation were based on a constant hardening speed and a maximal resistance threshold at the coleoptile stage of $-12{ }^{\circ} \mathrm{C}$ (Nos. 18, 14, 15 and 17). Standard deviation was minimized when the genotypic threshold for maximal resistance $R s$ was reached at the 3 leaf stage. No obvious conclusion could be made about the choice of the initial stage. Model 18 minimized the standard deviation criterion; it was also very satisfying for the mean of the absolute values of divergences $\left(1.14{ }^{\circ} \mathrm{C}\right)$ and the amplitude of divergences $\left(5.6^{\circ} \mathrm{C}\right)$. It is characterized by a constant hardening speed, a maximum resistance at the coleoptile stage of $-12{ }^{\circ} \mathrm{C}$ and a leaf range for the increase of maximum resistance from 0 up to 3.5. Therefore we chose to work with this model for the following discussion.

\subsubsection{Taking into account the genotypic differences for the hardening duration}

In our observations of frost damage, we regularly noted that the behavior of cultivars varied greatly according to the rapidity or earliness of the frost waves, or on the contrary, according to their lateness. These variations could result in changes in the classification of the cultivars. For early frost waves, we thus observed that the two cultivars Magali and Champlein could present the same frost sensitivity, or even be reversed. The same conclusions can be made for the three cultivars Cappelle, Capitole and Moisson. In the observations reported in this study, we observed that the resistance calculated for the cultivar Magali was underestimated in 1991/ 92 (as the frost appeared rapidly at a very young stage), that of Champlein, on the contrary, was overestimated in 1990/91 (as the frost also appeared at a young stage). The resistance of Cappelle was underestimated in 1993/1994 and in 1996/97 (as hardening was not complete) and that of Moisson was overestimated in 1995/1996.

Out of all these observations, we concluded that the cultivars Magali and Cappelle hardened more rapidly than the other cultivars, and on the contrary, Champlein and Moisson hardened more slowly. Therefore, we estimated again the frost resistance of these cultivars, assuming that the hardening speed was three weeks for Magali and Cappelle, and five weeks for Champlein and Moisson.

Table VI shows the results of the new prediction, using model 18. We observed that the mean divergence decreased 


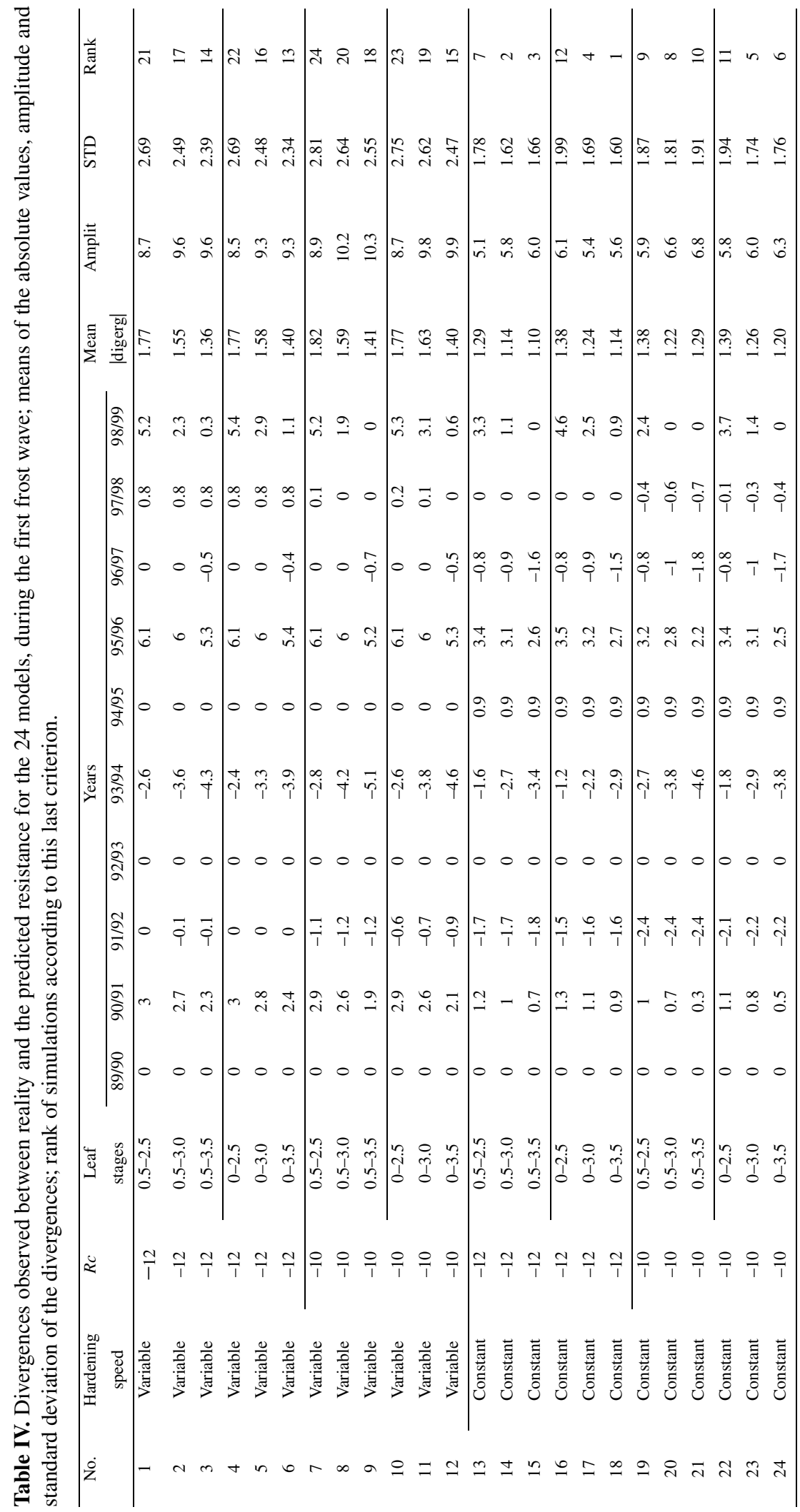


Table V. Analysis of variance of the absolute value of the yearly divergences between reality and predicted value obtained for each model.

\begin{tabular}{|c|c|c|c|c|c|c|c|c|}
\hline \multicolumn{2}{|c|}{ Source of variation } & \multirow{2}{*}{$\begin{array}{c}\mathrm{df} \\
9\end{array}$} & & \multirow{2}{*}{$\begin{array}{c}\text { Sum of squares } \\
468.417\end{array}$} & \multirow{2}{*}{$\begin{array}{c}\% \\
68.9\end{array}$} & \multirow{2}{*}{$\begin{array}{c}\text { Mean square } \\
52.046\end{array}$} & \multirow{2}{*}{$\begin{array}{c}\mathrm{F} \\
1081.18\end{array}$} & \multirow{2}{*}{$\begin{array}{c}\mathrm{Pr}>\mathrm{F} \\
*\end{array}$} \\
\hline Year & & & & & & & & \\
\hline Model & & 23 & & 10.910 & 1.6 & 0.474 & 9.862 & $*$ \\
\hline & Speed & & 1 & 6.734 & 1.0 & 6.734 & 139.88 & $*$ \\
\hline & $\mathrm{Rc}$ & & 1 & 0.171 & & 0.171 & 3.55 & \\
\hline & iLS & & 1 & 0.024 & & 0.024 & 0.50 & \\
\hline & fLS & & 2 & 3.263 & 0.5 & 1.631 & 33.89 & $*$ \\
\hline & Speed $\times$ Rc & & 1 & 0.028 & & 0.028 & 0.59 & \\
\hline & Speed $\times$ iLS & & 1 & 0.008 & & 0.008 & 0.17 & \\
\hline & Speed $\times$ fLS & & 2 & 0.494 & 0.1 & 0.247 & 5.13 & $*$ \\
\hline & $\operatorname{Rc} \times \mathrm{iLS}$ & & 1 & 0.054 & & 0.054 & 1.12 & \\
\hline & $\mathrm{Rc} \times \mathrm{fLS}$ & & 2 & 0.015 & & 0.008 & 0.16 & \\
\hline & $\mathrm{iLS} \times \mathrm{fLS}$ & & 2 & 0.035 & & 0.017 & 0.36 & \\
\hline & Rest of variation & & 9 & 0.084 & & 0.009 & 0.193 & \\
\hline Year $\times$ Speed & & 9 & & 93.882 & 13.8 & 10.431 & 216.69 & $*$ \\
\hline Year $\times \mathrm{Rc}$ & & 9 & & 8.668 & 1.3 & 0.963 & 20.01 & $*$ \\
\hline Year $\times$ iLS & & 9 & & 5.943 & 0.9 & 0.660 & 13.72 & $*$ \\
\hline Year $\times \mathrm{fLS}$ & & 18 & & 83.906 & 12.3 & 4.661 & 96.83 & $*$ \\
\hline Total of effects & & 77 & & 671.726 & 98.9 & 8.724 & 181.22 & $*$ \\
\hline Error & & 162 & & 7.798 & 1.1 & 0.048 & & \\
\hline Total & & 239 & & 679.524 & & & & \\
\hline
\end{tabular}

* Significant effect at the $5 \%$ level.

Student-Newman-Keuls test for a risk of 5\%.

\begin{tabular}{ccc}
\hline Years & Mean & \\
\hline $1995 / 96$ & 4.39 & A \\
$1993 / 94$ & 3.20 & B \\
$1998 / 99$ & 2.22 & C \\
$1990 / 91$ & 1.74 & D \\
$1991 / 92$ & 1.23 & E \\
$1996 / 97$ & 0.65 & F \\
$1994 / 95$ & 0.45 & G \\
$1997 / 98$ & 0.32 & H \\
$1989 / 90$ & 0.00 & I \\
$1992 / 93$ & 0.00 & I
\end{tabular}

\begin{tabular}{ccc}
\hline Speed & Mean & \\
\hline Variable & 1.59 & $\mathrm{~A}$ \\
Constant & 1.25 & $\mathrm{~B}$ \\
\hline
\end{tabular}

\begin{tabular}{cc}
\hline Initial stage & Mean \\
\hline 0 & 1.43 \\
0.5 & 1.41 \\
\hline
\end{tabular}

\begin{tabular}{cc}
\hline$R c$ & Mean \\
\hline-10 & 1.45 \\
-12 & 1.39 \\
\hline
\end{tabular}

\begin{tabular}{ccc}
\hline Final stage & Mean & \\
\hline 2.5 & 1.57 & $\mathrm{~A}$ \\
3.0 & 1.40 & $\mathrm{~B}$ \\
3.5 & 1.29 & $\mathrm{C}$ \\
\hline
\end{tabular}


Table VI. Comparison of the divergences between prediction and reality, using the reference model and the same model including the true hardening duration of the genotypes.

\begin{tabular}{lccccccccccccc}
\hline & $89 / 90$ & $90 / 91$ & $91 / 92$ & $92 / 93$ & $93 / 94$ & $94 / 95$ & $95 / 96$ & $96 / 97$ & $97 / 98$ & $98 / 99$ & $\begin{array}{c}\text { Mean } \\
\text { of } \\
\text { |divergences| }\end{array}$ & $\begin{array}{c}\text { Standard } \\
\text { deviation }\end{array}$ \\
\hline Reference model & 0 & 0.9 & -1.6 & 0 & -2.9 & 0.9 & 2.7 & -1.5 & 0 & 0.9 & 1.14 & 5.6 & 1.60 \\
New predictions* & 0 & 0 & $-\mathbf{0 . 8}$ & 0 & -2.9 & 0.9 & $\mathbf{1 . 5}$ & $\mathbf{- 0 . 1}$ & $\mathbf{- 0 . 2}$ & 0.9 & $\mathbf{0 . 7 3}$ & $\mathbf{4 . 4}$ & $\mathbf{1 . 2 0}$
\end{tabular}

* For the same model, including an hardening duration of 3 weeks for the genotypes Magali and Cappelle, 5 weeks for Champlein and Moisson.

from 1.14 to $0.73{ }^{\circ} \mathrm{C}$, the amplitude from 5.6 to $4.4{ }^{\circ} \mathrm{C}$, and the standard deviation from 1.60 to 1.20 . Prediction of the frost resistance of wheat cultivars up to the first frost wave was satisfying with the model made as described, but it could be further improved if we could integrate the real hardening speed of the cultivars. For any cultivar, this knowledge is generally not available, but one explanation for possible divergences between prediction and reality could be a longer hardening duration if the resistance is overestimated, and a shorter one if the resistance is underestimated.

\subsection{Evolution of the errors of prediction over the winter}

As expected, we observed increasing divergence between prediction and reality during successive frost waves in the same winter (Tab. VII). Divergences reached $11^{\circ} \mathrm{C}$ (in 1993/ 94 and 1997/98), amounting to $55 \%$ of the whole variation range of frost resistance for the cultivar Arminda in 1993/94. Concerning the different plant weakening factors being calculated, we also observed a great variability over the years: the frost wave duration varied from 1 to 22 days, the cumulated dehardening from 0 to $60 \%$ for the first frost wave, from 0.2 to $162 \%$ for the following ones, and the number of days when the resistance stayed very high from 0 to 70 .

Several correlations between divergence and these different variates were significant (Tab. VIII), the highest ones concerning cumulated dehardening expressed as raw values ( 0.647 with the variate $c u m D 2,0.561$ with the variate cumD1). Hence dehardening plays a leading part in plant weakening. These conclusions are consistent with those of Gusta and Fowler [15] showing that, after a variable time depending on temperature, wheat plants became unable to re-harden to their initial level. Then follows the correlation with the number of days when the acquired resistance stayed near the maximal resistance (NdMaxR): 0.462. At first, these observations seem to be inconsistent with those of Pomeroy et al. [28] and Gusta and Fowler [15], as these authors showed that a high and constant frost resistance can be prolonged for a very long time, if the temperatures the plants were exposed to were lower than or equal to $0{ }^{\circ} \mathrm{C}$ ( 12 weeks by the first authors, 120 days by the second ones). According to these observations, the number of days when the resistance remained high should not play a part, but in both cases, the temperature they were exposed to were near $0{ }^{\circ} \mathrm{C}$, whereas in our situations, the outside temperature was several times closer to the maximum resistance threshold of plants. Therefore, weakening of plants was more due to the occurrence of temperatures near the maximum resistance thresholds, even if they were higher than this threshold, rather than to the duration of the high hardened period.

The plant leaf stage is a measure of running time, but even if divergences increased with time within the same winter, we observed no correlation between divergence and leaf stage. The duration of frost waves also had little effect on the value of divergences. The number of frost waves is more important: in 1994/95, the leaf stage reached at the first frost wave was 6.2 , whereas the observed divergence was almost zero $\left(0.9^{\circ} \mathrm{C}\right)$.

We tried to relate the divergences between prediction and reality with plant weakening factors, using a linear regression, where the ordinate to zero point was fixed to 0 , as the predicted divergence had to be 0 for the first frost wave. Only two variates played a significant part in the regression: cumD2 and cumD3, which both describe the cumulated dehardening (Tab. IX). The third introduced variate was the cumulated duration of frost waves, but its effect was not significant. According to the best 2 covariates model, the explained part of variation was only $64.6 \%$, meaning that the factors accounted in our study were not sufficient to explain the weakening of wheat plants during the winter, even if dehardening played a leading part.

As observed by Fowler et al. [12], citing earlier works, an important reason for the decrease in hardening ability in wheat is the completion of the vernalization requirement: as a plant in the vegetative phase enters the reproductive one, the expression of genes involved in the frost resistance decreases. Improving our prediction model for further frost waves would include taking this factor into account. Fowler et al. [12] undertook such an approach, which may improve prediction of frost resistance for later frost waves.

Compared to the model of Fowler et al. [12], our model has the advantage of being based on observations of frost damages obtained in natural conditions. Additionally, it uses the temperature $2 \mathrm{~m}$ above the soil surface, being more adapted to the possibilities of measuring in the field. Our model can also be invoked to predict the frost resistance of all the wheat genotypes, provided that their frost resistance quotation is known. For their model, Fowler et al. [12] worked on one cultivar only, in which the maximal frost resistance threshold was determined on plants grown in the field, but removed and exposed to artificial frost in a controlled room. In the French conditions, most of the frost stresses can be considered as first 


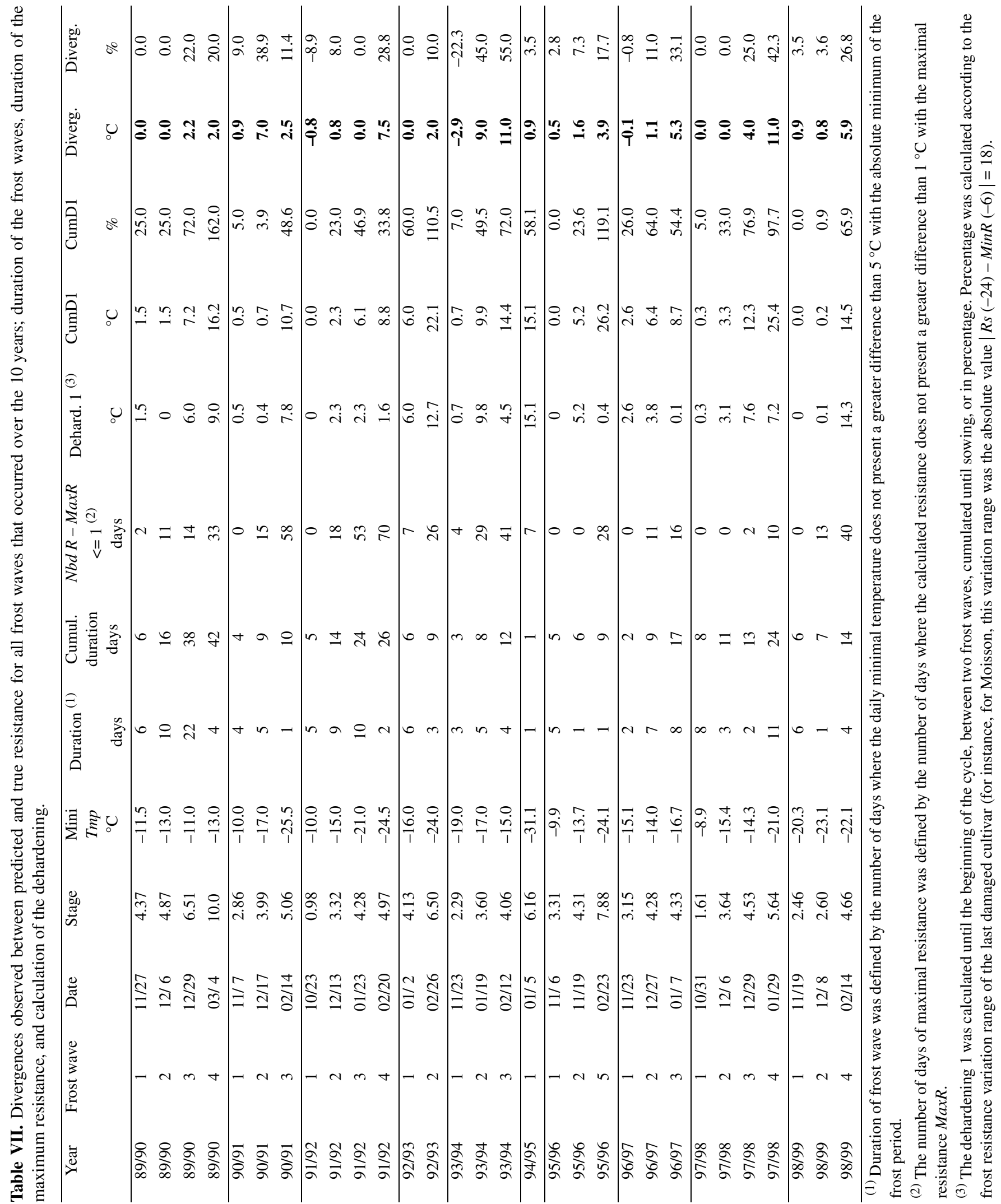


Table VIII. Correlation between divergences (predicted resistance/observed resistance) and different plant weakening factors.

\begin{tabular}{ccccccccccc}
\hline $\begin{array}{c}\text { Leaf } \\
\text { stage }\end{array}$ & $\mathrm{Ti}$ & Duration & $\begin{array}{c}\text { Cumul. } \\
\text { duration }\end{array}$ & Ndmaxr & Dehard1 & $\begin{array}{c}\text { Dehard1 } \\
\%\end{array}$ & Dehard2 & Dehard2 \% & Dehard3 & Dehard3 \% \\
\hline 0.265 & -0.234 & 0.026 & 0.296 & $0.462 *$ & $0.561 *$ & $0.369 *$ & $0.647 *$ & $0.477 *$ & $0.452 *$ & 0.288 \\
\hline
\end{tabular}

* Significant correlation at the $5 \%$ level.

Table IX. Best linear regression models (based on the highest $\mathrm{r}^{2}$ criterion) for the divergence, with 1, 2 or 3 covariates chosen among the plant weakening factors (variates in Tab. VII and Fig. 3); the ordinate to zero point is set to 0.

\begin{tabular}{ccccc}
\hline Model & & Covariates & Coefficients & $\begin{array}{c}\text { Adjusted determination } \\
\text { coefficient for the model }\end{array}$ \\
\hline 1 covariate & $1:$ & CumD2 $*$ & 0.413 & 0.591 \\
\hline 2 covariates & $1:$ & CumD2 $*$ & 0.775 & 0.646 \\
& $2:$ & CumD3 $*$ & -0.461 & 0.656 \\
\hline 3 covariates & $1:$ & CumD2 $*$ & 0.736 & -0.507 \\
& $2:$ & CumD3 $*$ & 0.057 & \\
\hline
\end{tabular}

\footnotetext{
* Significant effect at the $5 \%$ level.
}

frost waves, permitting us to assume that our prediction model may be most frequently adequate. Nevertheless, such a conclusion should be verified.

\section{CONCLUSIONS AND PERSPECTIVES}

We proposed several hypotheses to develop a model for predicting frost resistance of wheat. Simulated results were compared to frost damage observed over 10 years in natural conditions. This allowed us to indicate which components led to the best prediction model. Our best model includes:

- a maximum resistance of plants at the coleoptile stage of $-12{ }^{\circ} \mathrm{C}$;

- a progressive increase of the maximum resistance of plants until the 3.5 leaf stage; at the beginning of this increase, no difference appeared between the germination stage and the 0.5 leaf stage;

- a constant hardening speed during the hardening process, depending on the temperature the plants are exposed to.

Using these hypotheses, we verified that the model led to a good prediction of the frost resistance of different bread wheat cultivars for the first frost wave. This prediction was further improved if we took into account the true duration of hardening of the cultivars. In this case, the mean divergence between simulated and observed frost damages over 10 years was $0.73{ }^{\circ} \mathrm{C}$, the maximal divergence was $2.9^{\circ} \mathrm{C}$ (in $1993 /$ 1994), the amplitude of divergences was $4.4{ }^{\circ} \mathrm{C}$ and the standard deviation of divergences was 1.20.

Some improvement of prediction for later frost waves is possible, taking into account two cumulated dehardening criteria, one being calculated until the acquired resistance is near the maximum resistance allowed by the genotype and the growth stage, and another calculated until the resistance is near the maximum resistance of the genotype, regardless of the growth stage. But this improvement is not satisfactory, as the plant weakening is due to the combination of several factors which, individually, have not been clearly explained. Additionally, our study did not allow the validation of the hypotheses on which we worked concerning dehardening (equation for the dehardening speed, varying dehardening speed for different cultivars). Recent progress on this subject may lead us to a better consideration of these factors in order to improve the model. Specific studies on the individual behavior of the different genotypes also appear to be necessary.

The appearance of frost damage on a wheat plant is the first perceptible phenomenon, but generally it does not have any consequence on the future of the crop. We now are able to predict the appearance of damage but, however, it is possible to define temperature thresholds for damage of 10 or $50 \%$, or for the beginning of plant death. Such studies on the increase of damage as the temperatures the plants are exposed to get under the resistance threshold of the considered cultivar, will make it possible to integrate frost damage into a predictive model of the crop yield.

The model proposed here for wheat might to be extended to other species, provided that the genotypic maximum frost resistance thresholds are known, and that the hardening and dehardening processes are similar. This condition seems today to be satisfied $[4,18,19]$, particularly concerning the other cereals.

Acknowledgements: We expressly acknowledge Claire Chabanet, Jean-Marc Meynard, Richard Thompson and Sergio Ochatt for their precious contribution to the writing of this article. We also thank Gérard Doussinault, Maryse Brancourt, Virginie Bourion and Bertrand Schweisguth for their helpful reading of the manuscript.

\section{REFERENCES}

[1] Andrews C.J., Pomeroy M.K., Seaman W.L., The response of fallsawn cereals to winter stresses in Eastern Ontario, Can. J. Plant Sci. 66 (1986) 25-37. 
[2] Brule-Babel A.L., Fowler D.B., Genetic control of cold hardiness and vernalization requirement in winter wheat, Crop Sci. 28 (1988) 879-884.

[3] Charles B., Résistance au froid des blés, Agronomy Thesis, Institut Supérieur Agricole de Beauvais, France, 1979, p. 115.

[4] Cousin R., Résistance au froid et sélection chez le pois, Le Sélectionneur Français 31 (1983)17-28.

[5] Couvreur F., Gate P., Le gel constitue t-il un risque important?, Persp. Agric. 178 (1993) 76-81.

[6] Couvreur F., Dagneaud J.P., Massé J., Les céréales et le froid, Persp. Agric. 22 (1979) 12-21.

[7] Doussinault G., Kaan F., Lecomte C., Monneveux P., Les céréales à paille : présentation générale, in: Gallais A., Bannerot H. (Eds.), Amélioration des espèces végétales cultivées. Objectifs et critères de sélection, Editions INRA, 1992, pp. 13-21.

[8] Fowler D.B., Gusta L.V., Influence of fall growth and development on cold tolerance of rye and wheat, Can. J. Plant Sci. 57 (1977) 751-755.

[9] Fowler D.B., Gusta L.V., Selection for winter hardiness in wheat. I. Identification of genotypic variability, Crop Sci. 19 (1979) 769772.

[10] Fowler D.B., Siminovitch D., Pomeroy M.K., Evaluation of an artificial test for frost hardiness in wheat, Can. J. Plant Sci. 53 (1972) 53-59.

[11] Fowler D.B., Gusta L.V., Tyler N.J., Selection for Winterhardiness in Wheat. III. Screening Methods, Crop Sci. 21 (1981) 896-901.

[12] Fowler D.B., Limin A.E., Gusta L.V., Low-temperature Tolerance in Cereals: Model and Genetic Interpretation, Crop Sci. 39 (1999) 626-633.

[13] Gate P., Écophysiologie du blé ; de la plante à la culture, Ed. Lavoisier, Paris, 1995.

[14] GEVES (Groupe d'Étude des Variétés et des Semences), Bulletin des variétés, 2001.

[15] Gusta L.V., Fowler D.B., Effects of temperature on dehardening and rehardening of winter cereals, Can. J. Plant Sci. 56 (1976) 673-678.

[16] Gusta L.V., Fowler D.B., Dehardening and rehardening of springcollected winter wheats and a winter rye, Can. J. Plant Sci. 56 (1976) 775-779

[17] Gusta L.V., Fowler D.B., Factors affecting the cold survival of winter cereals, Can. J. Plant Sci. 57 (1977) 213-219.
[18] Herzog H., Influence of pre-hardening duration and dehardening temperatures on varietal freezing resistance in faba beans (Vicia faba L.), Agronomie 9 (1989) 55-61.

[19] Kacperska-Palacz A., Mechanism of cold acclimation in herbaceous plants, in: Li P.H., Sakai A. (Eds.), Plant cold hardiness and freezing stress. Mechanisms and crop implications, Vol. 1, Academic Press, New-York, 1978, pp. 261-272.

[20] Koller J., La résistance au froid du blé d'hiver, Le Producteur Agricole Français (1962) Vol. 6-7, p. 11.

[21] Koller J., Heinen A., Étude sur la résistance au froid des céréales à la station d'essais de Chaux-des-Prés (1950-1956), Bull. Tech. Inform. 116 (1957), p. 11.

[22] Kulesza L., Puckaki P., Kacperska A., Ice formation and frost killing temperatures as related to cold acclimation of winter rape plants, Acta Physiol. Plant. 8 (1986) 185-193.

[23] Lecomte C., Seuils de sensibilité au gel hivernal en grandes cultures, in: Riou C. (Ed.), Le gel en Agriculture, INRA, Commission d'Agrométéorologie, 1989, pp. 83-99.

[24] Lecomte C., Giraud A., Aubert V., Prise en compte des effets du froid hivernal dans l'élaboration du rendement du blé tendre. État actuel des travaux. Meeting of the scientists of the Cereal Group, INRA, Dijon, France, March 1994, pp. 23-25.

[25] Masle J., Sébillotte M., Étude de l'hétérogénéité d'un peuplement de blé d'hiver. II. Origine des différentes catégories d'individus du peuplement ; éléments de description de sa structure, Agronomie 1 (1981) 217-224

[26] Paquin R., Survie à l'hiver des plantes fourragères et des céréales sous les climats nordiques, en particulier au Québec : progrès et prospectives, Phytoprotection 66 (1985) 105-139.

[27] Pomeroy M.K., Fowler D.B., Use of lethal dose temperature estimates as indices of frost tolerance for wheat cold acclimated under natural and controlled environments, Can. J. Plant Sci. 53 (1973) 489-494

[28] Pomeroy M.K., Andrews C.J., Fedak G., Cold hardening and dehardening responses in winter wheat and winter barley, Can. J. Plant Sci. 55 (1975) 529-535.

[29] Roberts D.W.A., Duration of hardening and cold hardiness in winter wheat, Can. J. Bot. 57 (1979) 1511-1517.

[30] Sutka J., Genetic studies of frost resistance in wheat, Theor. Appl. Genet. 59 (1981) 145-152. 